\title{
Pesquisa-Ação na Construção de Insumos Conceituais de um Ambiente Computacional de Apoio ao Letramento Bilíngue de Crianças Surdas
}

\author{
Juliana Bueno ${ }^{1}$, Laura Sánchez García ${ }^{1}$ \\ ${ }^{1}$ Departamento de Informática - Universidade Federal do Paraná (UFPR) \\ Caixa Postal 19.081 - 81.531-980 - Curitiba - PR - Brasil \\ \{juliana, laura\}@inf.ufpr.br
}

\begin{abstract}
Bilingual literacy consists in making use of Sign Language (L1) for learning of a secondary oral language on written modality that for Brazilian students would be the Portuguese Language (L2). Unfortunately, Deaf education still doesn't have a practice of bilingual teaching/learning efficient. Motivated to revert this reality, this research adopts the action research (AR) methodology. AR made in a school of bilingual context throughout more than three years brought: (1) pedagogical benefits to the targeted school; (2) provided support for the conceptual solution of computational environment to support the bilingual literacy of Deaf children. User profiles and requirements are also described.
\end{abstract}

Resumo. O letramento bilíngue consiste em fazer uso da língua de sinais (L1) para o aprendizado de uma segunda língua oral na modalidade escrita, que no contexto brasileiro, é a Língua Portuguesa (L2). Infelizmente, a educação de surdos não possui ainda um processo de ensino/aprendizagem bilíngue eficiente. Motivado em reverter esta realidade, este trabalho toma como base os princípios da pesquisa-ação (PA). A PA ocorrida em uma escola de contexto bilingue teve mais de três anos de duração e: (1) trouxe beneficios pedagógicos à escola alvo; (2) deu suporte para um ambiente computacional de apoio ao letramento bilingue de crianças surdas. São descritos os perfis de usuário e os requisitos construídos para o ambiente.

\section{Introdução}

A comunidade surda vive, hoje, um período histórico de afirmação de seus direitos sociais que lhes foram negados por pelo menos um século. Ainda há muitos desafios que cercam a questão da inclusão social dos surdos, juntamente com a aceitação plena dos seus direitos e deveres na sociedade, que lhes permitam exercer plenamente a cidadania. Mesmo estando imersos em uma cultura majoritariamente oral, os surdos têm a sua própria comunidade e a sua própria língua, que é a língua de sinais (de caráter visual-espacial). Esta língua natural (mediadora dos processos de comunicação e de construção do conhecimento) e sua aquisição têm sido alvo de pesquisas que provaram tanto a sua validade linguística, como o seu papel fundamental no desenvolvimento intelectual [Chomsky 1998]. 
O presente trabalho se alinha com as escolhas políticas e ideológicas de Sánchez (1991), assumindo o contexto bilíngue como o adequado e optando pelo letramento de surdos instrumentado pela língua de sinais. O letramento bilíngue baseia-se no reconhecimento de que as crianças surdas são interlocutoras naturais de uma língua adaptada à sua capacidade de expressão. Ele se constitui pelo uso de, pelo menos, duas línguas: a língua de sinais, como "primeira língua" (L1) mesmo nos casos em que ela não seja cronologicamente a primeira língua adquirida, e uma segunda língua (L2), a língua do país onde a comunidade se insira. No contexto brasileiro, a L1 é a "Língua Brasileira de Sinais" (Libras) e a L2 é a Língua Portuguesa escrita.

Há, ainda, dentro da escola bilíngue, uma falta de métodos e práticas pedagógicas adequadas às formas como os surdos aprendem [Witkoski 2011]. Esta inadequação não se limita ao contexto brasileiro. Como apontam os estudos de [Marschark e Harris 1996], crianças surdas norte-americanas que se formam no ensino médio lêem, em média, no mesmo nível em que uma criança ouvinte de 8 a 9 anos de idade. Problemas semelhantes foram relatados em estudos realizados na Holanda [Wauters et al. 2006].

Diante desta realidade, o trabalho de tese relativo ao presente artigo foi desenvolvido ao longo de quatro anos, motivado pela situação de exclusão social da comunidade surda que tem, como fator determinante, a falta de práticas de ensino bilíngue próprias que foquem a Libras como primeira língua e mediadora da aquisição de uma segunda língua de modalidade oral, no caso, a Língua Portuguesa. O trabalho concentrou seus esforços em torno da questão: como um ambiente computacional poderia contribuir no letramento bilíngue dos surdos?

$\mathrm{Na}$ busca por respostas consistentes, este estudo genuíno (que proporcione as condições plenas para a aquisição de ambas as línguas) utilizou-se da pesquisa-ação (PA), que é um tipo de pesquisa social de base empírica, concebida e realizada em estreita associação com uma ação ou resolução de problemas dentro de uma atividade em que os pesquisadores e os participantes estão envolvidos em modo cooperativo ou participativo [Thiollent 2011]. A prática da PA proporcionou resultados qualitativos, causando um aumento de interesse de crianças surdas pela Língua Portuguesa escrita e, também, um processo mais consistente de aprendizagem dentro da escola alvo. Para a pesquisadora, os resultados da PA foram fundamentais para a etapa final, porque geraram insumos conceituais para o ambiente computacional de apoio ao letramento bilíngue de crianças surdas proposto. Adicionalmente, contribuíram na obtenção de 37 requisitos, na definição dos perfis de usuário (contemplados neste artigo) e na descrição da arquitetura preliminar do ambiente proposto.

\section{Fundamentação Teórica}

A metodologia adotada ao longo do trabalho foi multi e interdisciplinar, por abranger temas relacionados à Linguística (Letramento), Educação de Surdos, Ciência da Computação (Interação Humano-Computador e Informática na Educação), gerando resultados analíticos e empíricos. Desta forma, precisaram ser revisados conceitos de cultura, identidade, língua e linguagem pelo escopo sociointeracionista de Vygotsky e Bakhtin [Silva 2001], intercalados com uma literatura específica acerca dos surdos, com 
ênfase na importância da língua de sinais [Sánchez 1991; Fernandes 2011]. Foram também estudadas questões chave sobre: letramento, letramento bilíngue de surdos, letramento pela via direta apresentadas brevemente a seguir para melhor compreensão do trabalho.

\subsection{Letramento}

O letramento é o estado daquele indivíduo que sabe ler e escrever e que também faz uso pleno da leitura e da escrita. Ao tornar-se letrado, o indivíduo muda seu lugar social e seu modo de viver na sociedade garantindo sua inserção na cultura [Soares 2009]. Ele emerge no contexto das práticas sociais e culturais dos diversos grupos que usam a escrita, conferindo-lhe um domínio sociopolítico mais abrangente. Ele constitui um conjunto de práticas sociais que usam a escrita, como sistema simbólico e como tecnologia, em contextos específicos para objetivos específicos.

\subsection{Letramento Bilíngue de Surdos}

Este trabalho compartilha da ideia de Vygotsky (1989), que a forma escrita de uma língua oral pode ser aprendida diretamente, uma vez ela independe da língua oral, pois são sistemas diferentes tanto em estrutura quanto em natureza social. Ao conduzir o aprendiz surdo à língua dos ouvintes, deve-se situá-lo dentro do contexto valendo-se de sua língua "materna" (natural) [Salles et al. 2007].

Fernandes (2011) afirma que o desafio na educação de estudantes surdos está em oportunizar não apenas o acesso a experiências significativas de letramento, mas, sobretudo, em constituir uma prática bilíngue na qual a Libras esteja na centralidade das situações de enunciação. Já a Língua Portuguesa escrita, como segunda língua, possibilita a ampliação de suas relações sociais e a apropriação de elementos da cultura nacional, comuns a todos os brasileiros.

\subsection{Letramento pela Via Direta}

O letramento pela via direta, trabalhado em escolas francesas, belgas e brasileiras há mais de 40 anos com resultados comprovados, foi concebido pela AFL (Association Francese pour la Lecture - Associação Francesa pela Leitura) para o ensino de línguas estrangeiras. A metodologia parte dos pressupostos de que o letramento não é apenas uma decifração e que, a aquisição da cultura escrita em uma língua independe da oralidade (estas atuariam em progressões paralelas).

Segundo Razet (2012), da mesma forma que uma criança aprende a falar a partir das mensagens orais que lhe dirigimos, é a partir do sentido das mensagens escritas que o aluno adquire progressivamente o funcionamento do código gráfico, o que, na AFL, é chamado de "ir da mensagem ao código". Uma atividade de letramento é iniciada com um texto literário, o qual dá aporte para o trabalho com outros textos sociais. Pela visão da AFL, todo gênero textual é importante, não existindo subgênero.

O trabalho com o texto em si deve explorar: (1) a organização do texto (seu pertencimento a um gênero, suas articulações, sua estrutura, mas também suas relações com outros gêneros); (2) as estruturas gramaticais (a organização das frases, a 
pontuação, o encadeamento dos grupos de palavras, as expressões, o lugar dos componentes,...) e os efeitos produzidos pelas mudanças em relação às expressões esperadas; (3) as listas de palavras (campos lexicais, sonoridades, jogos sobre significados) e seus funcionamentos [Razet 2012].

\section{Trabalhos Relacionados}

O trabalho contou com uma investigação preliminar de pesquisas e soluções disponíveis. No contexto computacional brasileiro, foram encontrados cinco trabalhos que versam sobre o assunto do presente trabalho. Entretanto, em investigação mais aprofundada, constatou-se que quatro deles têm propostas metodológicas, finalidade e públicos diferentes [Santos et al. 2007; Holanda et al. 2005; Tavares 2009; Neto e Lorenzini 2009]. Um destes cinco trabalhos segue a mesma linha sociointeracionista do nosso e é direcionado a crianças surdas - KARYTU: um software para o letramento da criança surda sob a ótica bilíngue [Silva 2002]. No entanto, a tentativa de construção de conhecimento profundo sobre o mesmo mostrou uma falta de registro sobre os seus aspectos de inovação e de implementação.

Já o software Ideographix, lançado em sua primeira versão em 2002, foi resultado de três de processos de pesquisa-ação realizadas entre 1991 e 2000 no INRP (Institut National de Recherche Pédagogique - Instituto Nacional de Pesquisa Pedagógica) e pela AFL. Segundo Razet (2012), este software, fundamentado no letramento pela via direta, tem por objetivo permitir a melhor exploração da escrita de um texto e sua comparação com o funcionamento de outros. Ele permite maior rapidez nas pesquisas sobre um texto, sobre vários textos e sobre a língua de maneira geral, assim como a formulação de ferramentas de trabalho para os alunos.

O Ideographix é uma ferramenta "divisora de águas" no tratamento do trabalho com a língua escrita. Ele permite que professores tenham acesso pleno à informação constituinte de um texto e que se apropriem dela para o trabalho sistematizado com seus alunos. Ele também facilita a geração de exercícios para os alunos resolverem em sala de aula ou como tarefas de casa que despenderiam tempo significativo do professor, caso precisassem ser elaborados sem a ferramenta. Todas as funcionalidades que o software oferece são resultado da necessidade surgida na aplicação em contextos físicos, das práticas de ensino/aprendizagem do professor com seus alunos em sala de aula.

\section{Metodologia}

Com a problemática levantada, havia a necessidade de propor melhorias no processo de ensino/aprendizagem da escola alvo, sistematizando os conteúdos apresentados às crianças, a fim de propor um ensino bilíngue significativo e bem estruturado, antes mesmo de poder propor o modelo conceitual do ambiente computacional de apoio ao letramento de surdos. Então, pela abertura conquistada ao longo dos anos de convivência dentro da escola alvo, a pesquisa participante evoluiu, naturalmente, para uma pesquisa-ação.

Ao contrário das pesquisas tradicionais, que são consideradas independentes, objetivas e não reativas [Mctaggart 1996], a pesquisa-ação é "explicitamente democrática, colaborativa e interdisciplinar" [Hayes 2011, 3]. Ela visa, ao mesmo tempo, melhorar tanto o assunto estudado (muitas vezes chamado "cliente"), quanto à 
geração de conhecimento; a sua configuração depende dos seus objetivos e do contexto no qual é aplicada [Kock 2013].

No contexto da Interação Humano-Computador (IHC), nos últimos anos, a comunidade tem mostrado grande interesse em fazer pesquisa com valor social. A PA oferece uma abordagem colaborativa sistemática para a realização de pesquisas em IHC que satisfaz à necessidade de rigor científico e à promoção de mudança social sustentável [Hayes 2011]. Neste sentido, a PA oferece aos pesquisadores de IHC lentes teóricas, metodológicas e orientação pragmática para a construção de conhecimento credível no âmago de projetos colaborativos que envolvem democraticamente parceiros da comunidade no enfrentamento de desafios sociais importantes.

Uma das mais citadas versões do "Ciclo de Pesquisa-Ação" foi proposta por Gerald Susman e Roger Evered (1978) e compreende cinco estágios: (1) o estágio de Diagnóstico é onde o ciclo começa e envolve a identificação de uma oportunidade de melhoria ou um problema geral a ser resolvido na organização do cliente; (2) o estágio de Planejamento da Ação envolve a consideração de cursos alternativos de ação para atingir a melhoria ou resolver o problema identificado; (3) o estágio de Ação envolve a seleção e a implementação de um dos cursos de ação considerados na fase anterior; (4) o estágio de Avaliação envolve o estudo dos resultados do curso de ação selecionado; e (5) o estágio de Especificação do Aprendizado envolve a revisão dos resultados da fase de avaliação e, com base nela, a construção do conhecimento na forma de um modelo que descreve a situação em estudo. Sendo assim, todo o processo descrito a seguir baseou-se nos estágios descritos por estes autores.

O estágio de Diagnóstico: o ponto de vista externo da pesquisadora proporcionou uma melhor percepção dos problemas encontrados e uma contraposição do que a literatura indica como estratégias de letramento bilíngue de surdos eficazes e as maneiras como a escola as aplicam, ora de forma supérflua, ora de forma equivocada. Dos sete pontos chave levantados durante a pesquisa-ação como problemas elementares da escola alvo, o que para a pesquisadora se destacava como determinante do caráter inadequado do processo inicial de letramento era a exposição imediata da criança a imagens apenas precedidas da explicação em Libras e desconsiderando o texto em Língua Portuguesa em um primeiro momento.

O estágio de Planejamento da Ação: no início de 2013, houve uma abertura de diálogo com uma das professoras da escola alvo sobre os problemas observados durante as aulas, inclusive, nas dela. Após várias reuniões, a pesquisadora e a professora propuseram uma atividade prática de letramento bilíngue para o segundo semestre de 2013, com foco no contexto e no significado da Língua Portuguesa escrita. Tal atividade foi sistematizada e bem fundamentada, fazendo uma junção dos apontamentos sobre Letramento Bilíngue de Fernandes (2011) e da AFL. Todo o planejamento da atividade, bem como a busca por materiais de suporte e demais recursos para realização das aulas foi realizado em conjunto pela autora e a professora.

$O$ estágio de Ação: a atividade ocorreu com uma turma de $3^{\circ}$ ano do Ensino Fundamental e teve quatro crianças como participantes (dois meninos e duas meninas), com idades entre 8 a 9 anos, surdos profundos proficientes em Libras e que estudam na escola desde a Educação Infantil. Nenhuma das crianças do grupo possuía oralidade, ou 
fazia leitura labial. Por três meses, a atividade foi registrada por imagens e vídeos. Vale citar que, tal material documental teve prévia autorização de produção da escola e dos pais dos alunos participantes, que permitiram, também, o uso das imagens das crianças em publicações.

A professora iniciou a atividade de letramento com a contação de uma fábula em Libras (gênero literário). Em seguida, ela fez questionamentos acerca da fábula para instigar a imaginação das crianças. Diversas características da fábula foram trabalhadas. Por exemplo, em outra aula, as crianças receberam os parágrafos do texto recortados e tiveram que remontá-lo primeiro individualmente e em um segundo momento de forma coletiva (Figura 1). Depois, passou-se a outros gêneros textuais e sociais (revista, folhetos, encartes de viagem, entre outros) que tinham palavras ou assuntos correlacionados com a fábula trabalhada.

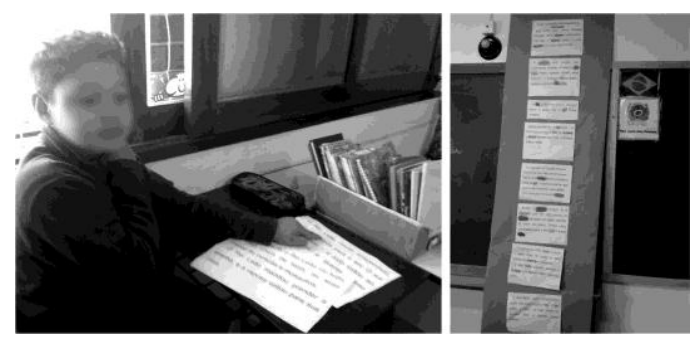

Fig. 1. Criança tentando organizar parágrafos de texto e organização coletiva da fábula fixada no quadro negro.

Assim, vários gêneros textuais (com temática e/ou vocabulário relacionado) foram trabalhados durante esta atividade, até as crianças terem aprendido várias palavras em Língua Portuguesa escrita (que para elas, agora tinham passado a ter significado) e terem alcançado autonomia para lerem um texto elas mesmas, sem apoio de recursos de imagens. Como reforço ao conteúdo aprendido, era solicitado que elas dramatizassem em Libras o texto lido (Figura 2).
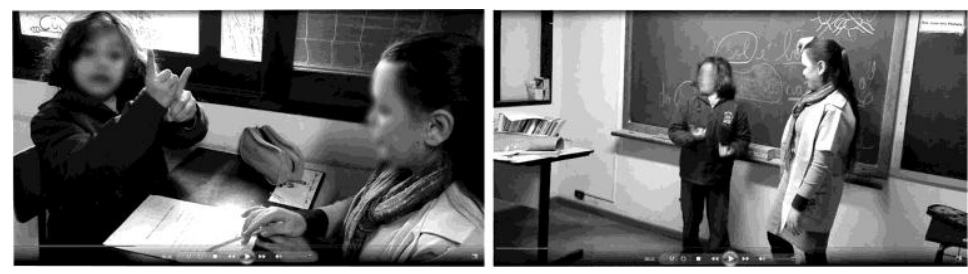

Fig. 2. Criança lendo e depois dramatizando o texto lido.

O estágio de Avaliação: para a professora da turma, foi instigante observar a autonomia das crianças diante da leitura do texto, mostrando que, a partir das informações com significado, por meio das palavras-chave, elas tinham conquistado a habilidade de fazer conexões entre tais informações e adquirido uma experiência mais significativa de leitura. Por conta do retorno positivo da atividade, a escola também ganhou destaque dentro do município e até internacionalmente. Para a pesquisadora deste trabalho, a atividade foi importante por ela ter lhe proporcionado uma melhor 
compreensão de como tal atividade poderia ser transformada em um processo e de como o artefato computacional poderia servir de instrumento mediador do binômio ensino/aprendizagem bilíngue para surdos.

O estágio de Especificação do Aprendizado: esta pesquisa-ação serviu como insumo para a geração de requisitos contemplados no corrente desenvolvimento do protótipo do ambiente computacional de apoio ao ensino bilíngue de crianças surdas.

\section{Resultados}

Como fontes de conhecimento que contribuíram efetivamente na construção do conjunto de requisitos principais do ambiente computacional destacam-se: Cultura e Identidade Surda; Letramento Bilíngue (Libras e Língua Portuguesa Escrita); Letramento pela via direta; Trabalhos relacionados, principalmente engenharia reversa do software Ideographix; Observações, durante 3 anos, das atividades de letramento de crianças surdas em contexto real; Atividades de letramento desenvolvidas durante a pesquisaação na escola alvo.

Ficou claro, ao longo do processo de PA, que este ambiente computacional de apoio ao letramento bilíngue de crianças surdas deve atender a dois perfis de usuário, devendo cada um dele, determinar um ambiente de interface e interação próprio: (a) o Professor (surdo ou ouvinte com fluência em Libras), cujo módulo o ajudará no planejamento de aulas, no planejamento dos exercícios a serem propostos aos alunos em sala de aula ou via computador, e na correção dos exercícios efetuados pelos alunos; (b) o Aluno (a criança surda ingressa na Educação Infantil até $5^{\circ}$ ano do Ensino Fundamental em um contexto de ensino bilíngue), ao qual o ambiente permitirá realizar as tarefas escolares planejadas pelo professor.

O conjunto de requisitos (no total de 37) foi organizado em: Gerais, do Professor, do Aluno, Ferramentas de Tratamento de Texto, de Imagens e de Vídeos, respectivamente. Na sequência, é apresentado um exemplo de requisito de cada categoria.

Requisito Geral (G9): upload e download de documentos em texto e vídeo (professor e aluno). Por exemplo: upload de vídeo de registro da dramatização de uma história infantil feita pelos alunos. Tanto o professor como o aluno deverão poder incluir documentos de hipermídia e interagir com eles durante a elaboração de material (de apoio didático ou de resposta ao exercício proposto).

Requisito específico ao ambiente do Professor (P2): possibilidade de inclusão de retorno sobre a solução apresentada pelo aluno a cada tarefa (notas, correções, explicações e sugestões de melhoria do texto escrito pelo aluno). Em outras palavras, a interação na correção das atividades realizadas pelo aluno deverá facilitar a inclusão e a organização de itens semânticos relevantes de praxe na prática didática.

Requisito especifico ao ambiente do Aluno (A4): possibilidade de criação de seus próprios dicionários com imagens associadas às palavras, às expressões aprendidas e aos sinais. Esta base de conhecimento multimídia e multimodal é crítica no tocante à 
apropriação do potencial inovador da tecnologia para a construção de conhecimentos linguísticos em contexto.

Requisito de Ferramentas para Tratamento de Texto (TT1): tratamento e diversas formas de visualização para marcação de texto em vários níveis com unidade e sentido: caractere, cadeias de caracteres (prefixo, morfema e sufixo de palavras, frases nominais e verbais, parágrafos, conjuntos de parágrafos). Embora claramente funcionais, requisitos como este são essenciais no suporte ao letramento pelo ambiente, na medida em que o caráter visual-espacial da língua de sinais dá legitimidade a estas formas de marcação e a todo o processo de interação por ela determinada.

Requisito de Ferramentas para o Tratamento de Imagem (TI11): edição de imagens (recorte, inibição, ampliação, destaque, entre outros), principalmente, para que textos sociais possam ser explorados junto aos alunos. Este requisito decorre do conceito de letramento, que envolve compreensão da informação subjacente às diversas formas de representação.

Requisitos de Ferramentas para o Tratamento de Video (TV2): ferramenta que possibilite ao professor a edição de vídeo, com sincronização para destaque no vídeo de expressões a serem trabalhadas no texto escrito ou material impresso digitalizado. A sincronização de segmentos de vídeo com trechos de texto escrito durante a interação do aluno com o ambiente, permitirá a observação e a análise comparativa entre as diferentes estruturas sentenciais da Libras e da Língua Portuguesa.

O ambiente computacional delineado envolve módulos correspondentes e é apoiado por uma série de bases de dados e bases de conhecimento. Ao elaborar um projeto, no sentido amplo, que envolve diversos gêneros textuais, o professor tem à sua disposição, bases de textos escritos, de imagens e vídeos. Ele tem a possibilidade de uso de dicionários, tanto da Língua Portuguesa, quanto da Libras. Adicionalmente, ele pode recorrer às bases que representam, respectivamente, as gramáticas da Língua Portuguesa e da Libras. O professor pode, também, consultar e atualizar o glossário da Língua Portuguesa para a Libras. Este glossário envolve, para cada palavra do Português, a sua explicação em Libras, os seus correspondentes em Datilologia e seus usos em contextos metafóricos, de sinonímia, de ironia, entre outros.

Já o aluno, ao visualizar o material e realizar as atividades terá, como principais suportes, os dicionários multilíngues, o glossário e o dicionário a Língua Portuguesa invertido (organizado para privilegiar a busca de palavras por sufixo). Ele poderá, ainda, criar seus dicionários pessoais multimídia.

\section{Conclusão}

O problema que mobilizou este trabalho foi a identificação da situação de exclusão social da comunidade surda devido a dois fatores determinantes: a falta de domínio da sua língua natural Libras e a falta de domínio da Língua Portuguesa escrita. Então, o seu objetivo foi propor um ambiente computacional de apoio ao letramento bilíngue de crianças surdas, onde o artefato computacional tivesse o papel de instrumento mediador 
do binômio ensino/aprendizagem, fazendo elo entre o professor (agente mediador) e o aluno (mediado) através da Libras (mediadora).

A metodologia adotada ao longo do trabalho foi multi e interdisciplinar; esta experiência proporcionou à pesquisadora a possibilidade de atestar a importância da língua de sinais para a aquisição de conhecimentos por parte dos surdos e, também, de levantar uma série de problemáticas no ensino bilíngue da escola alvo. Antes de propor uma solução conceitual de ambiente computacional, foi necessário investigar, construir e aplicar de forma integradora de teoria e prática, um processo metodológico e eficaz de ensino bilíngue.

Como estratégia, fez-se uso da PA, que levou ao planejamento em conjunto pela pesquisadora e pela professora regente da turma, de uma atividade de letramento bilíngue baseada método da AFL, de letramento pela via direta. Os resultados junto aos alunos foram satisfatórios e desencadearam um maior interesse e uma maior produtividade na Língua Portuguesa escrita. Para a pesquisadora, os anos de observações das práticas da escola somados à pesquisa teórica pertinente e a atividade de letramento aplicada contribuíram na definição dos perfis de usuário e na elaboração de 37 requisitos para o ambiente proposto.

O universo composto por 4 crianças surdas foi considerado válido pelas características intrínsecas à PA, em particular por ser um método qualitativo em essência e pelo fato da turma em questão ser uma turma real de número de alunos semelhante à media de alunos em turmas de escolas bilíngues de surdos.

Como principais contribuições, enxergam-se: (1) o processo de pesquisa como referência (com resultados comprovados e publicados) para pesquisadores atuantes simultaneamente nas áreas de Interação Humano-Computador e Informática na Educação continuarem fazendo pesquisa para o bem social; (2) a própria solução conceitual para o ambiente computacional no sentido de ela ser uma base suficientemente madura para ser utilizada em diversos trabalhos de pesquisa e desenvolvimento de caráter aplicado, hoje em andamento.

\section{Referências}

Chomsky, N. (1998) "Language and Problems of Knowledge", The Managua Lectures. The MIT Press, Cambridge.

Engel, G. I. (2000) "Pesquisa-Ação”, Educar. Curitiba: UFPR, 16, p. 181-191.

Fernandes, S. F. (2011) "Educação de Surdos”, Curitiba: IBPEX, 2ª ed.

Hayes, G. R. (2011) "The relationship of action research to human-computer interaction", ACM Trans. Comput.-Hum. Interact. 18, 3, Article 15.

Holanda, P. da S. et al. (2005) "ToonTalk na Educação de Crianças Surdas", XI Workshop de Informática na Educação - WIE, p. 2720-2728.

Kock, N. (2013) "Action Research: Its Nature and Relationship to Human-Computer Interaction", In: Soegaard, Mads and Dam, Rikke Friis (eds.). "The Encyclopedia of 
CBIE-LACLO 2015

Anais do XXVI Simpósio Brasileiro de Informática na Educação (SBIE 2015)

Human-Computer Interaction, 2nd ed." Aarhus, Denmark: The Interaction Design Foundation.

Marschark, M. e Harris, M. (1996) "Success and Failure in Learning to Read: The Special Case (?) of Deaf Children", In C. Cornoldi \& J. Oakhill (eds.), Reading comprehension disabilities: Processes and intervention (p. 279- 300). Hillsdale, NJ: LEA.

Mctaggart, R. (1996) "Issues for participatory action researchers", In New Directions in Action Research. Falmer Press.

Neto, C. e Lorenzini, I. P. (2009) "Sistema Tutor Inteligente para Auxílio na Alfabetização de Crianças Surdas em Contexto Bilíngue", XIV Workshop de Informática na Educação - WIE, p. 1773-1782.

Razet, C. (2012) "La lecture d'une histoire à La lecture d'une écriture", Synergies Brésil. Editora Humanitas, São Paulo, p. 59-74.

Salles, H. M. M. et al. (2007) "Ensino de lingual portuguesa para surdos: caminho para as práticas pedagógicas", SEESP, MEC, Brasília. Vol. 1 e 2.

Sanchez, C. (1991) "La educación de los Sordos en um modelo bilíngue", Mérida: Diakonia.

Santos, R. M. dos (2007) "Proposta de Arquitetura pedagógica para auxiliar formadores na Educação de Surdos”, XVIII Simpósio Brasileiro de Informática na Educação SBIE, p. 145-164.

Silva, A. C. (2002) "Karytu: um software para o letramento sob a ótica bilíngue", XII Simpósio Brasileiro de Informática na Educação - SBIE, p. 220-229.

Silva, M. P. M. (2001) “A construção de sentidos na escrita do aluno surdo”, São Paulo: Plexus, $4^{\text {a }}$ Ed.

Soares, M. (2009) "Letramento: um tema em três gêneros", Belo Horizonte: Autêntica Editora, $3^{\mathrm{a}}$ ed.

Susman, G. I. e Evered, R. D. (1978) "An Assessment of the Scientific Merits of Action Research", In Administrative Science Quarterly, 23, 4, p. 582-603.

Tavares, J. E. et al. (2009) "Uma Aplicação para o Ensino da Língua Portuguesa utilizando o SensorLibras", XX Simpósio Brasileiro de Informática na Educação SBIE.

Thiollent, M. (2011) “Metodologia da pesquisa-ação”, São Paulo: Cortez Editora.

Vygotsky L. S. (1989) “A formação social da mente”, Martins Fontes, São Paulo.

Wauters et al. (2006) "Reading comprehension of Dutch deaf children", Journal Reading and Writing: an interdisciplinary Journal, p. 46-76.

Witkoski, S. A. (2001) "Educação de surdos e preconceito: bilinguismo na vitrine e bimodalismo precário no estoque", Tese de Doutorado em Educação, Setor de Educação, da Universidade Federal do Paraná, Curitiba. 